\title{
Toric Orthokeratology Effectiveness on Correcting Astigmatism: A Narrative Literature Review
}

\author{
Shih Kae Chew* \\ University Isabel I de Castilla, Spain
}

Submission: July 13, 2018; Published: September 21, 2018

*Corresponding author: Shih Kae Chew, School of Advanced Education Research and Accreditation, C/ Germanas 31ํㅡ, 12001 Castellón de la Plana (Spain), Spain, Tel: 60182328345; Email: aovoptometrist@gmail.com

\begin{abstract}
Numerous studies demonstrated toric orthokeratology (Ortho-K) may reduce moderate to high astigmatism. Astigmatism commonly appears together with ametropia. Spherical Ortho-K lens is effective against low central corneal astigmatism, in patients with less than 1.50 D with-the-rule astigmatism. This review assesses toric orthokeratology studies performed by different researchers between 2007 and 2017. Author performed literature search for studies and case reports about toric Ortho-K, on scientific databases (PubMed, Wiley Online Library, ScienceDirect) and online journals Contact Lens \& Anterior Eye and Eye \& Contact Lens according to different inclusion and exclusion criteria. Eleven results describing toric Ortho-K were included in this review followed by a synthesis of findings. Results show that toric periphery/ alignment zone Ortho-K can improve lens centration for astigmatic correction and the combination of toric reverse zone and toric alignment zone (full toric/dual toric/real toric) is more effective for medium to high astigmatism. More published studies and statistical analysis are required to investigate the effectiveness of toric orthokeratology for medium to high astigmatism. Comparison of different type of toric orthokeratology design must be included for future research, as the published studies reviewed are mainly toric periphery, and full toric only appeared in case reports and editorials/anectodal.
\end{abstract}

Keywords: Toric orthokeratology; Refractive astigmatism; Corneal astigmatism; Toric periphery; Full toric

\section{Introduction}

Orthokeratology (orthoK) was first introduced in 1960s to slow down myopia progression. Orthokeratology lens is a reverse geometry gas permeable contact lenses, in which the curvature of the center is flatter than the periphery. They are available in spherical and toric design. OrthoK lenses temporarily improve uncorrected visual acuity (UCVA) in the daytime without spectacles or contact lenses, after overnight wear and removal of lenses upon wake up. OrthoK lenses flatten the central cornea, and their change in corneal power lead to a change in overall ocular refraction. Myopia is a common ocular disorder and high myopia is associated with higher risk of retinal disease, glaucoma and cataract. Myopia occurs at very young age and may progress very fast to high myopia. Astigmatism is a type of refractive error where the light does not focus evenly on retina, leading to blur vision at all distances. Astigmatism is due to differences in the curvature of the cornea or crystalline lens of the eye. In this review, we will focus on corneal astigmatism, not lenticular astigmatism. Astigmatism is associated with ametropia [1] and commonly co-exists with myopia. Many myopic patients are also astigmatic [2]. Spherical Ortho-K is effective in low to moderate myopia and low refractive astigmatism but is not sufficient for moderate refractive astigmatism [3]. Chang et al. [4] stated, "the incidence of astigmatism was about $33.6 \%$ in Asian children aged 5-17 years old and this value significantly increases with age". This review is important to search for suitable toric orthokeratology (toric Ortho-K) for reducing moderate to high astigmatism.

\section{Background}

The author has been fitting spherical Ortho-K to patients and would like to explore toric options for moderate to high corneal astigmatism. Astigmatism commonly appears together with ametropia. Spherical Ortho-K has diopter limit (D) for astigmatism correction

\section{Methods}

Author performed literature search for studies and case reports about toric Ortho- $\mathrm{K}$, on scientific databases (PubMed, Wiley Online Library, ScienceDirect) and online journal website Contact Lens \& Anterior Eye and Eye \& Contact Lens. Papers were included if they specifically focused on orthokeratology for myopia and astigmatism. Papers had to have a particular focus upon "toric orthokeratology" in order to be included within this literature review. Inclusion criteria for the papers are full article, English written, and published between 2007 and 2017. Case report and case series are included and articles outside of the time frame were included if they mentioned astigmatism changes. Articles that are non-English, not full text article and no source quoted are excluded. PubMed produced 17 results with "toric AND orthokeratology" search, Wiley produced 31 
results and ScienceDirect produced 55 results. Contact Lens \& Anterior Eye journal produced 55 results while Eye \& Contact Lens journal produced 73 results. Eleven results describing toric orthokeratology were included in this review.

Literature search using database and keywords

Literature Database:
1) Pubmed
2) Wiley Online Library
3) ScienceDirect

Online journal website:

1) Contact Lens and Anterior Eye

2) Eye $\&$ contact Lens
Inclusion criteria:

a) Full article

b) Year 2007-2017

c) English written

d) Case Report/Case Series

e) Article not in 2007-2017 but mentioned astigmatism changes in orthokeratology

Exclusion criteria:
A. Not full text article
B. Non-English article
C. No source quoted (Figure 1\&2)

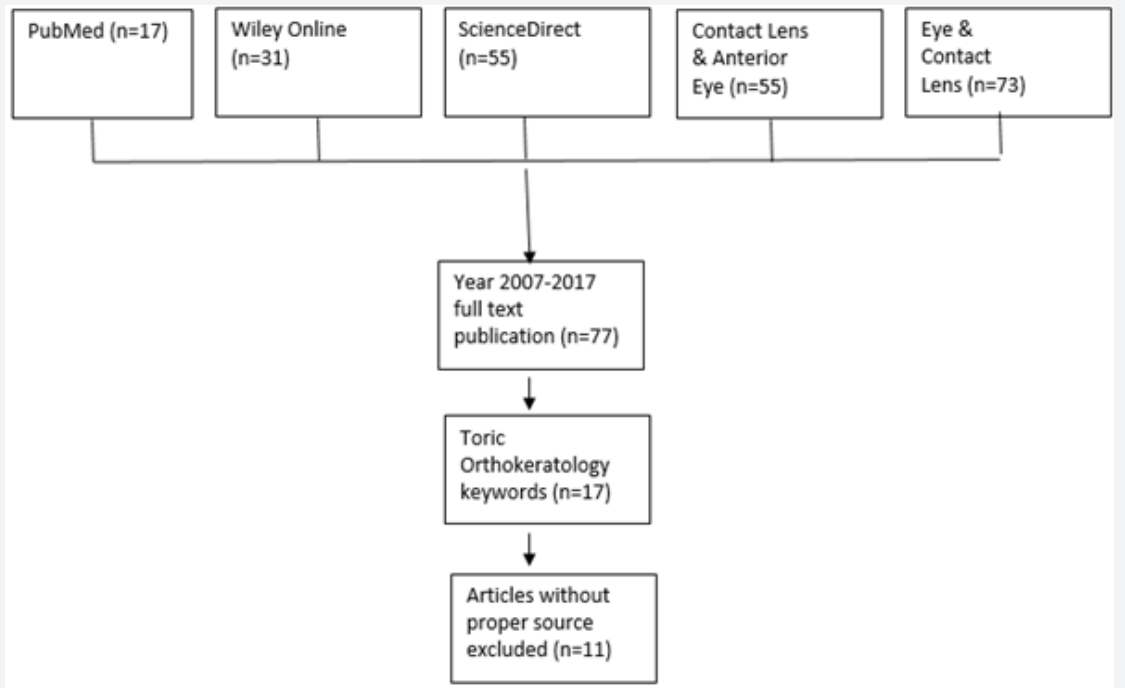

Figure 1: Results of literature search strategy.

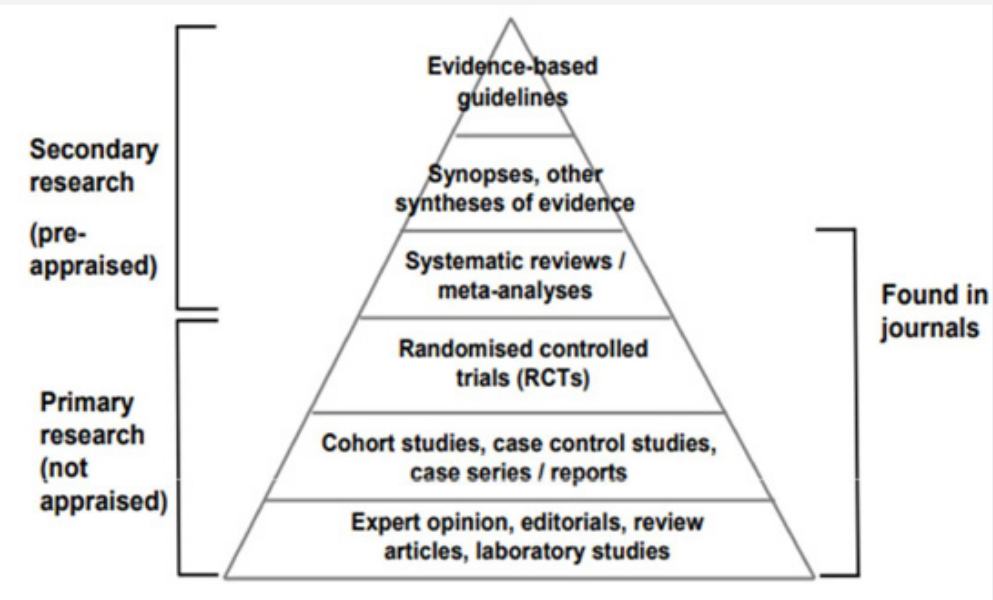

Adapted from (Haynes 2006).

Figure 2: Hierarchy of evidence. 


\section{Results}

1. This literature review has retrieved 11 papers using the keywords and inclusion and exclusion criteria.

2 . The articles reviewed in this study are categorized into primary source/secondary source (reviews) according to Hierarchy of evidence [5].

\section{Summary of Primary Sources Articles [6]}

Chen \& Cho [7] performed a case series using Menicon Z-Night toric periphery Ortho-K to limit myopia progression and correct the initial astigmatism in 2 subjects with high myopia and high astigmatism. Two subjects showed different responses to astigmatism reduction after 12 months. Chen, Cheung \& Cho [8] performed non-randomized longitudinal 2-years study using Menicon Z-Night toric periphery Ortho- $\mathrm{K}$ to determine toric Ortho-K effectiveness for myopia control in myopic children with moderate to high astigmatism in 80 subjects, with 43 Ortho-K subjects versus 37 control wearing single vision spectacle. Results showed astigmatism was reduced in Ortho-K group of subjects.

Chen, Cheung \& Cho [9] performed 1-month non-randomized longitudinal study, which is part of 2013 TO-SEE study in Paper 2. Same setting was applied and results showed toric Ortho-K reduce refractive astigmatism.

Chan, Cho \& De Vecht [10] presented a case report on single subject using Menicon Z-Night toric periphery for 15 months. Result showed toric periphery Ortho-K can be effective for high corneal astigmatism.

Chang et al. [4] performed retrospective, observational, double-blinded study for toric Ortho-K. They investigated and compared effectiveness of general and toric Ortho-K in corneal toricity in 19 subjects in Group I using spherical Ortho-K and 15 subjects in Group II using toric Ortho-K (toric alignment and Synthesis of the Findings

Table 1: Synthesis of the Findings.

\begin{tabular}{|c|c|c|c|c|c|}
\hline \multirow{2}{*}{$\begin{array}{c}\text { Variable/Main } \\
\text { Idea }\end{array}$} & \multicolumn{5}{|c|}{ Author/Sources } \\
\hline & $\begin{array}{c}\text { Chen \& Cho } \\
\text { [7] }\end{array}$ & $\begin{array}{c}\text { Chen et al. } \\
\text { [8] }\end{array}$ & $\begin{array}{c}\text { Chen et al. } \\
\text { [9] }\end{array}$ & $\begin{array}{c}\text { Chan et al. } \\
-2012\end{array}$ & $\begin{array}{c}\text { Chan et al. } \\
-2012 \\
\end{array}$ \\
\hline $\begin{array}{c}\text { Type of toric } \\
\text { Ortho-K } \\
\text { (Partial/Full toric) }\end{array}$ & $\begin{array}{c}\text { Type of toric } \\
\text { Ortho-K } \\
\text { (Partial/Full toric) }\end{array}$ & $\begin{array}{l}\text { Partial. Only } \\
\text { mentioned } \\
\text { toric lenses, } \\
\text { but } \\
\text { understood is } \\
\text { toric } \\
\text { periphery }\end{array}$ & $\begin{array}{c}\text { Partial. Toric } \\
\text { periphery }\end{array}$ & $\begin{array}{c}\text { Partial. Toric } \\
\text { periphery }\end{array}$ & $\begin{array}{l}\text { Group I:spherical } \\
\text { Group II: Full toric. } \\
\text { Toric periphery } \\
\text { +reverse. }\end{array}$ \\
\hline Brand name & $\begin{array}{c}\text { Menicon Z-Night } \\
\text { Toric }\end{array}$ & $\begin{array}{c}\text { Menicon Z-Night } \\
\text { Toric }\end{array}$ & $\begin{array}{c}\text { Menicon Z-Night } \\
\text { Toric }\end{array}$ & $\begin{array}{c}\text { Menicon Z-Night } \\
\text { Toric }\end{array}$ & $\begin{array}{l}\text { Lucid Korea toric } \\
\text { reverse and } \\
\text { alignment } \\
\text { curve }\end{array}$ \\
\hline $\begin{array}{l}\text { Fitting method } \\
\text { (Trial } \\
\text { fit/software) }\end{array}$ & Fitting software & Fitting software & Fitting software & Fitting software & $\begin{array}{c}\text { Trial fit. Not } \\
\text { mentioned } \\
\text { is spherical or toric } \\
\text { trial }\end{array}$ \\
\hline
\end{tabular}




\begin{tabular}{|c|c|c|c|c|c|}
\hline $\begin{array}{l}\text { Type of studies } \\
\text { and limitations }\end{array}$ & $\begin{array}{l}\text { Case series. Only } \\
2 \text { subjects }\end{array}$ & $\begin{array}{l}\text { Nonrandomized } \\
\text { longitudinal. } \\
\text { Nonrandomized } \\
\text { may have bias }\end{array}$ & $\begin{array}{c}\text { Nonrandomized } \\
\text { longitudinal. } \\
\text { Short } \\
\text { duration. }\end{array}$ & $\begin{array}{l}\text { Case report. } \\
1 \text { subject. } \\
\text { Small sample } \\
\text { size }\end{array}$ & $\begin{array}{c}\text { Retrospective } \\
\text { Observational; Double } \\
\text { blinded. Short } \\
\text { duration } \\
\text { and } 2 \text { different lens } \\
\text { design }\end{array}$ \\
\hline $\begin{array}{c}\text { Toric Ortho-K for } \\
\text { centration or } \\
\text { astigmatism } \\
\text { reduction }\end{array}$ & Both & Both & Both & Both & Both \\
\hline $\begin{array}{c}\text { Type of } \\
\text { astigmatism in the } \\
\text { studies }\end{array}$ & $\begin{array}{l}\text { Not specifically } \\
\text { mentioned. } \\
\text { From Rx power } \\
\text { is WTR }\end{array}$ & $\begin{array}{l}\text { WTR. Central } \\
\text { corneal } \\
\text { astigmatism }\end{array}$ & WTR & WTR & Not mentioned. \\
\hline $\begin{array}{c}\text { Refractive or } \\
\text { corneal } \\
\text { astigmatism } \\
\text { change (RA/CA) }\end{array}$ & RA and CA & RA and CA & RA and CA & RA and CA & RA and CA \\
\hline $\begin{array}{l}\text { Astigmatism } \\
\text { power range }\end{array}$ & $\begin{array}{c}\text { Subject 1: } \\
\text { CA } \\
\text { R:2.70D } \\
\text { L:3.40D } \\
\text { RA } \\
\text { R:2.25D; L:3.00D } \\
\text { Subject } 2: \\
\text { CA } \\
\text { R:3.40D } \\
\text { L:3.40D } \\
\text { RA } \\
\text { R:2.25D; L:2.50D }\end{array}$ & $\begin{array}{c}1.25 \mathrm{D} \text { to } \\
3.50 \mathrm{D} \\
\text { axis } 180 \pm 20\end{array}$ & $\begin{array}{c}1.25 \mathrm{D} \text { to } \\
3.50 \mathrm{D} \\
\text { axis } 180 \pm 20\end{array}$ & $\begin{array}{c}\text { RA R:1.50D } \\
\text { L:2.50D } \\
\text { CA R:2.40D } \\
\text { L:3.60D }\end{array}$ & $\begin{array}{l}\text { Toric subjects in } \\
\text { Group } \\
\text { II } \\
\text { RA: }-1.88 \pm 0.88 D\end{array}$ \\
\hline $\begin{array}{c}\text { Significance of } \\
\text { astigmatism } \\
\text { changes (Yes/No) }\end{array}$ & Yes & Yes & Yes & Yes & Yes \\
\hline $\begin{array}{l}\text { Define moderate } \\
\text { and high } \\
\text { astigmatism } \\
\text { (Yes/No) }\end{array}$ & No & $\begin{array}{l}\text { Yes. }>1.50 \\
\text { cylinder }\end{array}$ & $\begin{array}{c}\text { No. WTR } \\
\text { astigmatism } \\
1.25 \mathrm{D} \text { to } 3.50 \\
\text { D for axes } \\
180 \pm 20\end{array}$ & $\begin{array}{c}\text { Yes. WTR } \\
\text { corneal } \\
\text { toricity }<1.50 \mathrm{D} \\
\text { as low to } \\
\text { moderate, high } \\
\text { corneal toricity } \\
\text { for } \\
\text { WTR }>1.50 \mathrm{D} \text {. }\end{array}$ & No \\
\hline $\begin{array}{l}\text { Vector analysis } \\
\text { application } \\
\text { (Yes/No) }\end{array}$ & No & No & $\begin{array}{l}\text { Yes. Power } \\
\text { vectors }\end{array}$ & No & $\begin{array}{l}\text { Yes. Thibos vector } \\
\text { analysis }\end{array}$ \\
\hline
\end{tabular}

In this review, the researchers from the papers retrieved are put into two groups. Group 1 used toric periphery Ortho-K (also known as toric alignment zone) and group 2 used full toric Ortho-K (toric alignment and reverse zone). In group 1 , Chen \& Cho [7], Chen et al. [8], Chen et al. [9] and Chan et al. [10] used Toric periphery Ortho-K (spherical design at back optic zone and reverse zone of the lens, toric at alignment zone) in their studies. In group 2, Chang et al. [4], López-López et al. [11], Baertschi \& Wyss [12], Luo et al. [13], Pauné et al. [14], Byul et al. [15] and Calossi [16] used Full toric Ortho-K (toric at reverse zone, alignment zone, and may extend to toric back optic zone) in their studies.(Table 1)

\section{Type of Toric Ortho-K and Brand Name}

Byul L et al. [15] did not mention type of toric Ortho-K specifically in their studies, as each brand name may have toric periphery or full toric (toric alignment and reverse zone). Full toric Precilens (France) in Pauné et al. [14] study consists of five toric area which produce double tear reservoir (double reverse zone), Whether this design would further reduce astigmatism compared with two toric area (toric alignment and reverse zone) would require further study in the future. The purpose of designing toricity in optical zone and having opposite meridian steepness in optical and alignment zone is unknown. 
Table 2: Synthesis of the Findings.

\begin{tabular}{|c|c|c|c|c|c|c|}
\hline \multirow[b]{2}{*}{$\begin{array}{l}\text { Variable/Main } \\
\text { Idea }\end{array}$} & \multicolumn{6}{|c|}{ Author/Sources } \\
\hline & $\begin{array}{c}\text { López-López et } \\
\text { al. [11] }\end{array}$ & $\begin{array}{c}\text { Baertschi } \\
\text { \& Wyss } \\
{[17]}\end{array}$ & Luo et al. [13] & $\begin{array}{c}\text { Pauné et al. } \\
\text { [14] }\end{array}$ & $\begin{array}{l}\text { Byul et al. } \\
\text { [15] }\end{array}$ & Calossi [16] \\
\hline $\begin{array}{l}\text { Type of toric } \\
\text { Ortho-K } \\
\text { (Partial/Full } \\
\text { toric) }\end{array}$ & $\begin{array}{l}\text { Full toric. Toric } \\
\text { landing+reverse } \\
\text { zone. }\end{array}$ & Full toric. Toric & $\begin{array}{c}\text { Full toric. Toric } \\
\text { alignment+reverse } \\
\text { zone }\end{array}$ & $\begin{array}{c}\text { Full toric. Toric } \\
\text { Optic } \\
\text { Zone(BOZR)+toric } \\
\text { periphery. } 5 \text { toric } \\
\text { area, } 2 \text { reverse } \\
\text { zone }\end{array}$ & $\begin{array}{l}\text { Not mentioned } \\
\text { is partial or } \\
\text { full toric }\end{array}$ & Full toric. \\
\hline Brand name & $\begin{array}{c}\text { Dual Axis } \\
\text { Paragon CRT }\end{array}$ & FOKX toric & $\begin{array}{l}\text { Lucid night toric } \\
\text { (reverse and } \\
\text { alignment) }\end{array}$ & $\begin{array}{l}\text { Precilens Full } \\
\text { toric double } \\
\text { reservoir }\end{array}$ & Lucid Toric & $\begin{array}{c}\text { ESA bitorica } \\
\text { (hexacurve,dual toric } \\
\text { in optical and } \\
\text { alignment zone) }\end{array}$ \\
\hline $\begin{array}{c}\text { Fitting } \\
\text { method (Trial } \\
\text { fit/fitting } \\
\text { software) }\end{array}$ & $\begin{array}{l}\text { Trial fit with } \\
\text { spherical and } \\
\text { order toric }\end{array}$ & $\begin{array}{c}\text { Fitting } \\
\text { software }\end{array}$ & $\begin{array}{l}\text { Trial fit and/or } \\
\text { software. }\end{array}$ & Fitting software & Trial fit & Not mentioned \\
\hline $\begin{array}{c}\text { Type of } \\
\text { studies and } \\
\text { limitations }\end{array}$ & $\begin{array}{l}\text { Case report. } 1 \\
\text { subject }\end{array}$ & $\begin{array}{c}\text { Case } \\
\text { report. } 1 \\
\text { subject. } \\
\text { No } \\
\text { duration } \\
\text { mentioned }\end{array}$ & $\begin{array}{c}\text { Case series } \\
\text { without control } \\
\text { group }\end{array}$ & $\begin{array}{c}\text { Retrospective } \\
\text { studies. Retro } \\
\text { limit data } \\
\text { collection. May } \\
\text { underestimate } \\
\text { change in } \\
\text { refractive } \\
\text { cylinder }\end{array}$ & $\begin{array}{l}\text { Case report. } \\
\text { Short } \\
\text { duration } \\
\text { and no } \\
\text { control } \\
\text { group. }\end{array}$ & $\begin{array}{l}\text { Case report. } 1 \\
\text { subject. }\end{array}$ \\
\hline $\begin{array}{l}\text { Toric Ortho-K } \\
\text { for centration } \\
\text { or } \\
\text { astigmatism } \\
\text { reduction }\end{array}$ & Both & Both & Both & Both & Both & Both \\
\hline $\begin{array}{c}\text { Type of } \\
\text { astigmatism } \\
\text { in the studies }\end{array}$ & Limbus-to-limbus & WTR & WTR & $\begin{array}{l}\text { ATR:6 eyes } \\
\text { Central vs } \\
\text { limbusto- } \\
\text { limbus not } \\
\text { analysed }\end{array}$ & $\begin{array}{c}\text { Corneal } \\
\text { astigmatism } \\
\text { exclude } \\
\text { limbus- } \\
\text { tolimbus }\end{array}$ & $\begin{array}{c}\text { WTR. Astigmatism } \\
\text { component>spherical } \\
\text { component }\end{array}$ \\
\hline $\begin{array}{l}\text { Refractive or } \\
\text { corneal } \\
\text { astigmatism } \\
\text { change } \\
\text { (RA/CA) }\end{array}$ & RA and CA & RA and CA & RA and CA & RA and CA & RA and CA & RA \\
\hline $\begin{array}{l}\text { Astigmatism } \\
\text { power range }\end{array}$ & $\begin{array}{c}\text { RA R:-0.75DC } \\
\text { L:-1.00DC } \\
\text { CA R:1.25 D } \\
\text { L:1.50 D }\end{array}$ & $\begin{array}{l}\text { RA R: - } \\
\text { 3.75 DC } \\
\text { CA R: } \\
\text { 3.10D }\end{array}$ & $\begin{array}{l}\text { RA: } 1.50 \text { to } 3.50 \mathrm{D} \\
\mathrm{CA}: 2.27 \pm 0.57 \mathrm{D}\end{array}$ & $\begin{array}{c}\text { RA more than } \\
1.25 \mathrm{D} \text { at any } \\
\text { orientation }\end{array}$ & $\begin{array}{c}\text { RA } 1.25 \text { to } \\
4.00 \mathrm{D}\end{array}$ & $\begin{array}{l}\text { RA R:-2.00DC } \\
\text { L:-2.25DC }\end{array}$ \\
\hline $\begin{array}{l}\text { Significance of } \\
\text { astigmatism } \\
\text { changes } \\
\text { (Yes/No) }\end{array}$ & Yes & Yes & Yes & Yes & Yes & Yes \\
\hline $\begin{array}{c}\text { Define } \\
\text { moderate and } \\
\text { high } \\
\text { astigmatism } \\
\text { (Yes/No) }\end{array}$ & No & No & No & No & No & No \\
\hline
\end{tabular}




\begin{tabular}{|c|c|c|c|c|c|}
\hline $\begin{array}{c}\text { Vector } \\
\text { analysis } \\
\text { application } \\
\text { (Yes/No) }\end{array}$ & No & No & No & Yes. Thibos vector & No \\
\hline
\end{tabular}

As this review only involves one paper describing a five toric area double reservoir, author suggests future toric Ortho-K category for: simple toric Ortho-K (toric periphery), full toric (toric alignment and reverse zone), real toric (more than one reverse reservoir) for comparison.(Table 2)

\section{Fitting method using trial lenses or software-based}

Astigmatic cornea has different types of astigmatism (corneal central astigmatism, limbus-to-limbus, oblique, WTR and ATR), thus there is a trend now using software for toric Ortho-K lens design. Higher astigmatism may require software fitting as different corneal meridian requires different lens toricity for reducing astigmatism. In this review, we shall look at each study apply empirical software fit or trial fitting. Chen \& Cho [7], Chen et al. [8], Chen et al. [9] and Chan et al. [10] used Menicon Easy Fit Software for Menicon Z-Night Toric Ortho-K

Table 3: Group 1 and Group 2 researchers. empirical fit. Baertschi \& Wyss [12], and Pauné et al. [14] depended on Ortho-K software for the lens fitting, but the name of the software was not specifically mentioned.

In the Lucid Toric study by Luo et al. [13], the researcher mentioned trial lens fit but did not specifically mention using a set of Ortho-K trial lenses or combination of software and trial lenses. Chang et al. [4] used trial fit but did not mention using spherical or toric Ortho-K trial lenses in Lucid Toric study. Byul et al. [15] used trial lens for their study, but again, they did not mention type of trial lenses in the Lucid Toric trial fitting. LópezLópez et al. [11] performed trial fit using spherical Paragon CRT trial lens, combined with last topography, over-refraction results to manufacturer to calculate the dual axis Paragon CRT parameters. No software is available at researcher for empirical fitting procedure. Calossi [16] did not mention empirical or trial fit in the ESA bitorica Ortho-K lens fitting.(Table 3 \& 4)

\begin{tabular}{|c|c|}
\hline Group 1 Toric Periphery Ortho-K & Group 2 Full Toric Ortho-K \\
\hline Chen and Cho [7] & Chang et al. [4] \\
\hline Chen et al. [8] & López-López et al. [11] \\
\hline Chen et al. [9] & Baertschi \& Wyss [17] \\
\hline Chan et al. [10] & Luo et al. [13] \\
\hline & Pauné et al. [14] \\
\hline & Byul et al. [15] \\
\hline & Calossi [16] \\
\hline
\end{tabular}

Table 4: Group 1 and Group 2 researchers.

\begin{tabular}{|c|c|c|}
\hline Group 1 Researchers & Toric Periphery brand name & Full Toric brand name \\
\hline Chen \& Cho [7] & Menicon Z-Night Toric & \\
\hline Chen et al. [8] & Menicon Z-Night Toric & \\
\hline Chen et al. [9] & Menicon Z-Night Toric & $\begin{array}{c}\text { Lucid Korea Toric Reverse } \\
\text { and alignment curve }\end{array}$ \\
\hline Chan et al. [10] & Menicon Z-Night Toric & Dual Axis Paragon CRT \\
\hline & Group 2 Researchers & FOKX Toric \\
\hline Chang et al. [4] & & $\begin{array}{c}\text { Lucid Night Toric(reverse } \\
\text { and alignment curve) }\end{array}$ \\
\hline López-López et al. [11] & & $\begin{array}{c}\text { Precilens Full toric Double } \\
\text { Reservoir }\end{array}$ \\
\hline Baertschi \& Wyss [17] & & Lucid Toric \\
\hline Luo et al. [13] & Lucid Toric & $\begin{array}{c}\text { ESA bitorica (hexacurve, dual } \\
\text { toric in optical and alignment } \\
\text { zone) }\end{array}$ \\
\hline Pauné et al. [14] & & \\
\hline Byul et al. [15] & & \\
\hline Calossi [16] & & \\
\hline
\end{tabular}

Fitting method by using spherical trial lenses but delivered lens is a toric Ortho-K may not be a good option. To maximize the toric Ortho-K effect on reducing astigmatism, we may need a combination of Ortho-K fitting software and trial fitting with toric Ortho-K lenses. 
In this review section, we discovered Menicon Z-Night toric provides Easy Fit software for examiner to perform empirical fit at examiner terminal. FOKX toric requires fitting software at the lab terminal and parameters decided by the lab. Lucid toric requires trial lens or combination of trial lens and fitting software, and whether the software at examiner or lab terminal cannot be confirmed. Whether combination of toric trial lenses and fitting software will be a better option depends on future study.

\section{Type of studies and their limitations}

Chen \& Cho [7] conducted a toric Ortho-K case series research which involved two subjects, one subject did not return after twelve months monitoring. Chen et al. [9] did a non-randomized study for one-month duration, which formed part of 2013 nonrandomized longitudinal two years study, involving 80 subjects (43 Ortho-K subjects vs. 37 control). There may be systematic bias due to non-randomized study [8]. Chan et al. [10] conducted one high astigmatic case report on toric periphery Ortho-K and managed to show great reduction of corneal toricity in right eye by 87.5 percent and 67.6 percent in left eye.

A retrospective observational study involving 34 cases was done by Chang et al. [4] for three months duration. This study is double blinded as both the researchers and subjects do not know

Table 5: Type of toric Ortho-K studies.

\begin{tabular}{|c|c|c|c|c|}
\hline Group 1 Researchers & Type of study & Subject sample & Duration & Remarks \\
\hline Chen and Cho [7] & Case Series & 2 & 12 months & \\
\hline Chen et al. [8] & $\begin{array}{c}\text { Non-randomised } \\
\text { longitudinal }\end{array}$ & 80 & 24 months & TO-SEE \\
\hline Chen et al. [9] & $\begin{array}{l}\text { Non-randomized } \\
\text { longitudinal }\end{array}$ & 80 & 1 month & Part of TOSEE \\
\hline Chan et al. [10] & Case report & 1 & 15 months & \\
\hline \multicolumn{5}{|c|}{ Group 2 Researchers } \\
\hline Chang et al. [4] & $\begin{array}{c}\text { Retrospective } \\
\text { Observational; } \\
\text { Double blinded }\end{array}$ & $\begin{array}{c}19 \text { spherical } \\
\text { Ortho-K; } 15 \text { toric } \\
\text { Ortho-K }\end{array}$ & 3 months & \\
\hline López-López et al. [11] & Case report & 1 & 12 months & \\
\hline Baertschi and Wyss [17] & Case report & 1 & 2 months & \\
\hline Luo et al. [13] & $\begin{array}{c}\text { Case series without } \\
\text { control group }\end{array}$ & 24 & 12 months & \\
\hline Pauné et al. [14] & $\begin{array}{l}\text { Retrospective } \\
\text { studies }\end{array}$ & 32 & $\begin{array}{l}\text { Jan } 2008- \\
\text { Dec-10 }\end{array}$ & $\begin{array}{l}\text { Right eye } \\
\text { only }\end{array}$ \\
\hline Byul et al. [15] & $\begin{array}{l}\text { Single group clinical } \\
\text { trial }\end{array}$ & 19 & 1 month & \\
\hline Calossi [16] & Case report & 1 & 18 months & \\
\hline
\end{tabular}

Although astigmatism correction in Ortho-K is limited to $1.50 \mathrm{D}$, but astigmatism commonly co-exists with myopia and there is trend the higher astigmatism is increasingly popular. Author included the toric Ortho-K case reports in this review as there are limited studies that specifically look into astigmatism changes. the design of lenses. The limitation is short duration and has two different lens designs, one spherical and one toric design, sourced from different manufacturers. López-López et al. [11] performed a full toric study in a case report of single subject, for one year of duration. We are not sure why the researcher performed trial fitting using spherical Ortho-K and the lab decided the toric lens design with results submitted by the researcher. Obviously this is a case of limbus-to-limbus astigmatism and spherical has little chances to achieve good centration, shown in the result of the study. Baertschi \& Wyss [12] presented a case report for a single subject using full toric Ortho-K lens but did not specify the study duration. Luo et al. [13] self-controlled clinical study is a case series without control group, involving 24 subjects for one-year duration. Pauné et al. [14] performed retrospective studies for 32 patients from Jan 2008 to Dec 2010. Byul et al. [15] conducted a case series involving 23 subjects for four weeks duration. The study duration is short and there was no control group available. Calossi [16] presented a case report using full toric but that is limited to a single subject, with astigmatic component higher than spherical component.

Although case reports and case series showed promising results in reducing moderate to high astigmatism with toric Ortho-K lens, we shall need a larger subject group and prefer a randomized control study for a statistical analysis.(Table 5) 


\section{JOJ Ophthalmology}

reduction as full toric provides perfectly closed reverse-zone in every meridian, but this will need a larger subject group and randomized studies.

Centration is very important before the toric Ortho- $\mathrm{K}$ can be effective on reducing astigmatism. A decentered lens may increase instead of decreasing the amount of astigmatism [17].

\section{Type of astigmatism in the studies}

Chen \& Cho [7] did not specifically mention the type of astigmatism, but from the refractive errors in the study, it was With-the-rule (WTR) astigmatism. WTR astigmatism was used in the studies of Chen et al. [8], Chen et al. [9], Chan et al. [3], Baertschi and Wyss [17], Luo et al. [13] and Calossi [16]. Central corneal astigmatism was specifically mentioned in the study by Chen et al. [8].

Table 6: Type of astigmatism in different studies.

\begin{tabular}{|c|c|c|c|c|}
\hline Group 1 Researchers & $\begin{array}{c}\text { WTR } \\
\text { astigmatism }\end{array}$ & $\begin{array}{c}\text { ATR } \\
\text { astigmatism }\end{array}$ & $\begin{array}{l}\text { Limbus-to- } \\
\text { Limbus }\end{array}$ & Others \\
\hline Chen and Cho [7] & $\sqrt{ }$ & & & \\
\hline Chen et al. [8] & $\sqrt{ }$ & & & \\
\hline Chen et al. [9] & $\sqrt{ }$ & & & \\
\hline Chan et al. [10] & $\sqrt{ }$ & & & \\
\hline \multicolumn{5}{|c|}{ Group 2 Researchers } \\
\hline Chang et al. [4] & & & & $\begin{array}{c}\sqrt{ } \text { not } \\
\text { mentioned }\end{array}$ \\
\hline López-López et al. [11] & & & $\sqrt{ }$ & \\
\hline \multicolumn{5}{|l|}{ Baertschi \& Wyss [17] } \\
\hline Luo et al. [13] & $\sqrt{ }$ & & & \\
\hline Pauné et al. [14] & $\sqrt{ }$ & $\sqrt{ }$ & & $\begin{array}{c}\sqrt{ } \text { including } \\
\text { oblique }\end{array}$ \\
\hline Byul et al. [15] & $\sqrt{ }$ & & & $\begin{array}{c}\sqrt{\text { not }} \\
\text { mentioned }\end{array}$ \\
\hline Calossi [16] & $\sqrt{ }$ & & & \\
\hline
\end{tabular}

\section{Refractive astigmatism or corneal astigmatism changes and their power range}

Table 7: Range of astigmatism in studies and type of changes.

\begin{tabular}{|c|c|c|}
\hline Group 1 Researchers & Range of astigmatism being studied & $\begin{array}{c}\text { Refractive astigmatism (RA)/ } \\
\text { Corneal astigmatism* (CA) }\end{array}$ \\
\hline \multirow{2}{*}{ Chen \& Cho [7] } & $\begin{array}{c}\text { Subject 1: CA RE:2.70D; LE:3.40D } \\
\text { RA RE:2.25D; LE:3.00D } \\
\text { Subject 2: CA RE:3.40D; LE:3.40D } \\
\text { RA RE:2.25D; LE:2.50D }\end{array}$ & RA and CA \\
\hline Chen et al. [8] & RA and CA \\
\hline Chen et al. [9] & RA to 3.50D axis 180 250 & RA and CA \\
\hline Chan et al. [10] & RA R:1.50D L:2.50D & CA R:2.40D L:3.60D \\
\hline
\end{tabular}




\begin{tabular}{|c|c|c|}
\hline \multirow{2}{*}{ López-López et al. [11] } & RA R:-0.75 DC; L:-1.00 DC & RA and CA \\
\hline \multirow{2}{*}{ Baertschi \& Wyss [17] } & CA R:1.25 D ; L:1.50 D & RA and CA \\
\hline Luo et al. [13] & RA R: -3.75 DC & RA and CA \\
\hline Pauné et al. [14] & RA: 1.50 to 3.50D & RA and CA \\
\hline Byul et al. [15] & CA: $2.27 \pm 0.57 \mathrm{D}$ & RA and CA \\
\hline Calossi [16] & RA more than 1.25D at any orientation & RA \\
\hline
\end{tabular}

All researchers reported that both refractive astigmatism had changed. Note that Calossi [16] study involved refractive and corneal astigmatism (corneal toricity) changes took place, except in Calossi [16] which showed only refractive astigmatism astigmatism which is higher than spherical power.(Table 7)

Table 8: Significance of astigmatism changes.

\begin{tabular}{|c|c|c|}
\hline Group 1 Researchers & Changes of astigmatism & Significant \\
\hline & & (Yes/No) \\
\hline Chen \& Cho [7] & $\begin{array}{l}\text { Subject 1: Almost full astigmatism reduction } \\
\text { (12 months) } \\
\text { Subject 2: 30-40\% astigmatism reduction } \\
\text { (12 months) }\end{array}$ & Yes \\
\hline Chen et al. [8] & $\begin{array}{l}\text { RA: }-1.86 \pm 0.64 \mathrm{D}-0.37 \pm 0.39 \mathrm{D}(6 \text { months }) \\
\text { CA: }-2.28 \pm 0.53 \mathrm{D} \text { not mentioned }\end{array}$ & Yes \\
\hline Chen et al. [9] & $\begin{array}{l}\text { RA:1.91 } \pm 0.64 \text { à } 0.88 \pm 0.59 \mathrm{D}(1 \text { night }) ; 59 \% \\
\text { reduction } \\
\text { à } 0.40 \pm 0.39 \mathrm{D}(1 \text { month); } 79 \% \text { reduction } \\
\text { CA: } 2.30 \pm 0.51 \text { à } 2.01 \pm 0.61 \mathrm{D}(1 \text { night }) ; 13 \% \\
\text { reduction } \\
\text { à1.28 } \pm 0.53 \mathrm{D}(1 \text { month); } 44 \% \text { reduction }\end{array}$ & Yes \\
\hline Chan et al. [10] & $\begin{array}{l}\text { RA: R:1.500.50D ; L:2.500.75 D (15 months) } \\
\text { CA: R:2.401.20D ; L:3.601.20 D (15 months) }\end{array}$ & Yes \\
\hline \multicolumn{3}{|c|}{ Group 2 Researchers } \\
\hline Chang et al. [4] & $\begin{array}{l}\text { Astigmatism J0 component reduced } 61 \% \text { after } \\
3 \text { months } \\
\text { J0:-1.19 } \pm 0.25 \mathrm{D}-0.46 \pm 0.84 \mathrm{D}\end{array}$ & Yes \\
\hline López-López et al. [11] & RA R:-0.75Dplano ; L:-1.00 Dplano (1 year) & Yes \\
\hline Baertschi \& Wyss [12] & RA R: -3.75 D -0.50 D & Yes \\
\hline Luo et al. [13] & $\begin{array}{l}\text { RA: }-1.81 \pm 0.53-0.41 \pm 0.39 \text { D ( } 1 \text { month }) \\
\text { CA: } 2.27 \pm 0.57 \mathrm{D} 1.48 \pm 0.47 \text { D ( } 1 \text { month) } \\
1.27 \pm 0.43 \text { D (12 months) }\end{array}$ & Yes \\
\hline Pauné et al. [14] & $\begin{array}{c}\text { RA: }-2.18 \pm 1.36-0.38 \pm 0.41 \mathrm{D} \text { (retrospective) } \\
\text { CA: }-2.40 \pm 1.27-1.30 \pm 0.69 \mathrm{D}\end{array}$ & Yes \\
\hline Byul et al. [15] & RA $2.07 \pm 0.831 .44 \pm 0.99 \mathrm{D}(4$ weeks) & No \\
\hline Calossi [16] & $\begin{array}{l}\text { RA R:-2.00DC -0.75DC (1 week) } \\
\text {-0.50DC (3 months) } \\
\text { L:-2.25DC-1.00DC (1 week) } \\
\text {-1.00DC (3 months) }\end{array}$ & Yes \\
\hline
\end{tabular}

\section{Significance of astigmatism changes}

When we look at this review section of main ideas, take note that significant is not statistically significant, as some studies are not statistically analysed. Significant changes implied the astigmatism reduction is more than $0.75 \mathrm{D}$ in refractive astigmatism or corneal astigmatism/toricity. The table shows that astigmatism changes are significant with both toric periphery (toric alignment zone) and full toric (toric alignment and reverse zone), except in Byul et al. [15].(Table 8)

Take note the reported significant changes may only involve a small sample subjects in case report or case series. We shall have more reliable results if we have a larger sample with control group and longer study duration. 
Byul et al. [15] results showed small change of astigmatism may be due to undefined type of astigmatism, non-specified type of toric Ortho-K, and short study duration. Calossi [16] case report showed there is residual astigmatism at the third month. At the 18th month, residual astigmatism was not mentioned. We must be cautious when treating patients with higher cylinder component than spherical component, and patient consultation is very important to meet their expectations.

\section{Definition of moderate and high astigmatism}

Chen and Cho [7], Chang et al. [4], López-López et al. [11], Baertschi \& Wyss [17], Luo et al. [13], Pauné et al. [14], Byul et al. [15] and Calossi [16] did not define the range of moderate or high corneal astigmatism. Chen et al. [9] did not define the moderate or high astigmatism in their one-month study, but provided inclusion criteria for WTR astigmatism 1.25D to $3.50 \mathrm{D}$ for axes $180 \pm 20$. Chen et al. [8] defined high corneal astigmatism for subjects more than $1.50 \mathrm{D}$ cylinder. Chan et al. [10] defined WTR corneal toricity less than $1.50 \mathrm{D}$ as low to moderate astigmatism, and high corneal toricity for WTR astigmatism more than 1.50D. As the population's average astigmatism will change over time, it is imperative to define low/moderate/high astigmatism and updates made known, for Ortho-K fitter and examiner to have a better guideline for toric Ortho-K cases.

\section{Vector Analysis application}

The researchers that used vector analysis for refractive astigmatism and corneal astigmatism changes are Chen et al. [9] who used Power vectors, Chang et al. [4] who used CRAVY vector analysis and Pauné et al. [14] who used Thibos vector. Vector analysis is important to assess the corneal changes induced by Ortho-K lens in pre- and post-treatment [18]. Mountford \& Pesudovs [18] stated there are three types technique used: Bailey-Carney vector analysis, Alpins vector analysis and Corneal topography analysis. Whether corneal topography analysis replaced the first two analysis or vector analysis still has its value, we shall leave it to the future researcher who may look into this.

\section{Discussion}

Spherical Ortho-K lenses can reduce corneal astigmatism up to $1.50 \mathrm{D}$ with-the-rule astigmatism at the central 2 millimetre chord [18]. In this review, we look at relationship between toric Ortho-K and moderate to high astigmatism.

Although Chen \& Cho [7], Chen et al. [8], Chen et al. [9] and Chan et al. [10] used Toric periphery Ortho-K in their studies, all results show significant change of refractive astigmatism. The studies by Chang F et al. [4], López-López et al. [11], Baertschi \& Wyss [17], Luo et al. [13], Pauné et al. [14], Byul et al. [15] and Calossi [16] showed significant change in refractive astigmatism and corneal astigmatism.

It was interesting to note that Group 1 researchers' intention of using toric periphery Ortho- $\mathrm{K}$ is for better centration of Ortho-K lenses on astigmatic cornea, resulting in reduction of astigmatism. Group 2 researches using Full toric Ortho-K aim at myopia control and reduction of astigmatism. Baertschi \& Wyss [17] pointed that the correction of corneal astigmatism requires a perfectly closed reverse-zone in every meridian and that is only possible with toric reverse zone Ortho-K lenses. The majority of the studies reviewed involved a small amount of subjects. We shall need a bigger sample of subjects to study toric Ortho-K effect on correcting astigmatism, specifically refractive and corneal astigmatism.

Different researchers may have their own definition of moderate to high astigmatism. We shall need a common agreement on the range of moderate to high astigmatism in future studies for comparison. We need to categorize the toric Ortho-K (partial, full, real) and disclose their specifications to determine the effectiveness of correcting astigmatism in any study. Ortho-K fitters may need to work closely with Ortho-K lab for various options in cases of myopic with low astigmatism, myopic with high astigmatism, high myopic with low astigmatism, high myopic with high astigmatism, astigmatism component is higher than myopic component, hyperopic with astigmatism, limbusto-limbus astigmatism and presbyopic with astigmatism.

Author is concerned about reduction of astigmatism as astigmatism commonly co-exists with myopic patients [19] and a higher astigmatism is getting more common (Harvey et al. 2006). Prevalence of astigmatism is as high as that of myopia in Korea and East Asia at $60 \%$, and this value significantly increases with age [20]. The myopia control effect of orthokeratology will be less than successful if residual refractive error of astigmatism is high and cannot be corrected. These particular subjects who undergone the orthokeratology will have poor visual acuity when the lenses are removed upon wake up. Toric Ortho- $\mathrm{K}$ is important in helping the subject undergone myopia control and allow subjects to see clear without the lenses in daytime, by correcting the astigmatism or kept to the minimum. The results of this review provide new and united evidence to toric Ortho-K effectiveness in correcting astigmatism. This new evidence will be important to encourage future study to apply randomized controlled trial with toric Ortho-K. If we continue focus only on myopia with low astigmatism, we deprive the opportunity of moderate to high astigmatism subjects to receive "free from spectacles in the daytime" and myopia control effects [21-29].

\section{Conclusion}

It is important to explore toric Ortho- $\mathrm{K}$ effectiveness in correcting astigmatism, both refractive and corneal type. This paper has reviewed the evidence between toric Ortho- $\mathrm{K}$ and astigmatism. Following the review of 11 academic papers, the evidence presented here suggested that toric Ortho-K reduce astigmatism and provide good lens centration on astigmatic cornea.

As well as discovering that toric Ortho- $\mathrm{K}$ is able to reduce astigmatism, this review has also unearthed that different type of toric Ortho-K (toric periphery and full toric) has different effectiveness on low and moderate to high astigmatism. 
In summary, Toric Ortho- $\mathrm{K}$ is effective for lens centration and for correcting medium to high astigmatism. More published studies and statistical analysis are required to investigate the effectiveness of toric orthokeratology for medium to high astigmatism. Comparison of different type of Toric Orthokeratology design must be included for future research, as the published studies reviewed are mainly toric periphery, and full toric only appeared in case reports and editorials/anectodal

\section{Acknowledgments}

I would like to thank Mr. Raúl Pérez of the School of Advanced Education, Research and Accreditation (SAERA), Spain, as the reader of this thesis, and I am gratefully indebted to him for his very valuable comments on this thesis.

Besides Mr Raúl Pérez, I would like to thank Dr. Chan Mooi Kwai of University of Science Malaysia (USM, Molecular medicine) for her insightful comments and encouragement, but also for the hard question which incented me to widen my research from various perspectives.

My sincere thanks also go to Oliver Gubler, Managing Director of Falco Linsen AG, who provided access to the information of FOKX toric orthokeratology lenses.

Finally, I must express my very profound gratitude to my family and friends for providing me with unfailing support and continuous encouragement throughout my study and through the process of researching and writing this thesis. This accomplishment would not have been possible without them. Thank you.

\section{References}

1. Duke-Elder (1970) Anomalies of refraction. System of Ophthalmology. pp. 274-292

2. Fan DS, Rao SK, Cheung EY, Islam M, Chew S, et al. (2004) Astigmatism in Chinese preschool children: prevalence, change, and effect on refractive development. Br J Ophthalmol 88: 938-941.

3. Cheung SW, Cho P, Chan B (2009) Astigmatic changes in orthokeratology. Optom Vis Sci 86(12): 1352-1358.

4. Chang F, Wang T, Chen X, Chen Y, Li Mei, et al. (2017) The effectiveness of general and toric orthokeratology lenses in corneal toricity. Biomed Res 28(20): 8832-8838.

5. Haynes (2006) Critical appraisal of a journal article.

6. Cronin P, Ryan F, Coughlan M (2008) Undertaking a literature review: a step-by-step approach. Br J Nurs 17:1:41

7. Chen C, Cho P (2012) Toric Orthokeratology for high myopic and astigmatic subjects for myopic control. Clin Exp Optom 95(1): 103-108.

8. Chen C, Cheung SW, Cho P (2013) Myopia control using toric orthokeratology (TO-SEE study). Invest Ophthalmol Vis Sci 54(10): 6510-6517.

9. Chen CC, Cheung SW, Cho P (2012) Toric orthokeratology for highly astigmatic children. Optom Vis Sci 89(6): 849-855.

10. Chan B, Cho P, de Vecht A (2009) Toric orthokeratology: a case report. Clin Exp Optom 92(4): 387-389.

11. López-López, Pelegrín-Sánchez, Sobrado-Calvo and García-Ayuso (2011) Contact lens intolerance: refitting with dual axis lens for corneal refractive therapy. J Optom 4(1): 4-8.
12. Baertschi M, Wyss M, Kummer J, Bolli S, Frankhauser M (2017) Can you be a bit more (Quadrant) Specific?

13. Luo M, Ma S, Liang N (2014) Clinical efficacy of toric orthokeratology in myopic adolescent with moderate to high astigmatism. Eye Science 29(4): 209-213.

14. Pauné J, Cardona G, Quevedo L (2012) Toric double tear reservoir contact lens in orthokeratology for astigmatism. Eye \& Contact Lens 38(4): 245-251.

15. Byul L, Kyu Yeon H, Sun Young K, Su Young K, Kyug Sun N (2016) Effectiveness of toric orthokeratology in the treatments of patients with combined myopia and astigmatism. Korean J Ophthalmol 30(6): 434-442.

16. Calossi A (2013) Mixed astigmatism treated with a dual-toric ortho-k design. CL Spectrum 38: 49.

17. Baertschi M, Wyss M (2010) Correction of high amounts of astigmatism through orthokeratology. A case report. J Optom 3(4): 182-184 .

18. Mountford J, Pesudovs K (2002) An analysis of the astigmatic changes induced by accelerated orthokeratology. Clin Exp Optom 85(5): 284293.

19. Wen G, Tarczy-Hornoch K, McKean-Cowdin R, Cotter SA, Borchert M, et al. (2013) Prevalence of myopia, hyperopia, and astigmatism in nonHispanic white and Asian children: multi-ethnic pediatric eye disease study. Opthalmology 120(10): 2109-2116.

20. Yoon KC, Mun GH, Kim SD, Kim SH, Kim CY (2011) Prevalence of eye diseases on South Korea: data from the Korea National Health and Nutrition Examination Survey 2008-2009. Korean J Opthalmol 25(6): 421-433.

21. Chan B, Cho P, Cheung SW (2008) Orthokeratology practice in children in a university clinic in Hong Kong. Clin Exp Optom 91(5): 453-460.

22. Cho P, Cheung SW (2012) Retardation of Myopia in Orthokeratology (ROMIO) study: A 2-Year Randomized Clinical Trial. Investigative Ophthalmology \& Visual Science 53(11): 7077-7085.

23. Cho P, Cheung SW, Edwards M (2005) The longitudinal orthokeratology research in children (LORIC) in Hong Kong: a pilot study on refractive changes and myopia control. (ABSTRACT) Curr Eye Res 30(1): 71-80.

24. Fadel D (2016) Unusual Clinical Cases in Orthokeratology. Review of Cornea \& Contact Lenses.

25. Fadel D (2017) Reshaping Ortho-k. Review of Cornea \& Contact Lenses.

26. Grewal A, Kataria H, Dhawan I (2016) Literature search for research planning and identification of research problem. Indian J Anaesth 60(9): 635-639.

27. Huang J, Wen D, Wang Q, McAlinden C, Flitcroft I, et al. (2016) Efficacy Comparison of 16 Interventions for Myopia Control in Children. Opthalmology 123(4): 697-708.

28. Jeffry J. Walline, Marjorie J Rah, Lisa A Jones (2004) The Children's Overnight Orthokeratology Investigation (COOKI) Pilot Study. Optom Vis Sci 81(6): 407-413.

29. Patrick J and Mark P (2002) Should Most Orthokeratology Lenses Be Toric? Contact Lens Spectrum 31: 56. 


Your next submission with Juniper Publishers
will reach you the below assets
- Quality Editorial service
- Swift Peer Review
- Reprints availability
- E-prints Service
- Manuscript Podcast for convenient understanding
- Global attainment for your research
- Manuscript accessibility in different formats
( Pdf, E-pub, Full Text, Audio)
- Unceasing customer service
Track the below URL for one-step submission
https://juniperpublishers.com/online-submission.php

